\title{
Haemato-biochemical studies in medically managed open and closed-cervix pyometra in dogs ${ }^{\star}$
}

\author{
D. Nayana ${ }^{1+*}$, B. Bibin Becha ${ }^{2}$, C. Jayakumar ${ }^{3}$, M.P. Unnikrishnan ${ }^{4}$ and Syam K. Venugopal ${ }^{5}$ \\ Department of Animal Reproduction, Gynaecology and Obstetrics, \\ College of Veterinary and Animal Sciences, Mannuthy, Thrissur - 680651 \\ Kerala Veterinary and Animal Sciences University, Kerala, India.
}

Citation: Nayana, D., Becha, B.B., Jayakumar, C., Unnikrishnan, M.P. and Venugopal, S.K. 2021. Haemato-biochemical studies in medically managed open and closed-cervix pyometra in dogs. J. Vet. Anim. Sci. 52(3): 281-285. DOI: https://doi.org/10.51966/jvas.2021.52.3.281-285

Received: 03.02.2021

Accepted: 16.03.2021

Published: 30.09 .2021

\begin{abstract}
Six dogs each with open and closed-cervix pyometra (Group I and II) were medically managed with mifepristone @ 2.5mg/kg body weight orally twice daily for five days, followed by cloprostenol @ 5 $\mathrm{\mu g} / \mathrm{kg}$ body weight subcutaneously on every alternate day after ensuring cervical patency, till complete evacuation of uterus was assessed by ultrasonography. Haematological and serum biochemical values were estimated on the day of presentation. The treatment response was assessed by reviewing both haematological and serum biochemical values further on days 3, 7, 14 and 21 of treatment. The mean total erythrocyte count (TEC), haemoglobin concentration and volume of packed red cells (VPRC) were significantly lower and mean total leucocyte count (TLC) was significantly higher in all animals of both groups during the day of presentation. The values significantly improved after initiation of treatment. Total thrombocyte count, serum total protein, albumin, BUN and serum creatinine levels were within the normal range. TEC, TLC, Hb concentration, VPRC could be used for prognostic markers of treatment evaluation in canine pyometra.
\end{abstract}

\section{Keywords: Pyometra, haemato-biochemistry, medical management}

Cystic endometrial hyperplasia-pyometra (CEH-P) is one of the life threatening uterine pathological conditions affecting mostly the aged, intactfemale dogs, characterised by accumulation of purulent material inside the uterine lumen. Under the influence of progesterone there will be enhanced endometrial glandular proliferation and increased glandular secretion. This will favour the multiplication of commensal bacteria to many folds and result in pyometra. Based on the

\footnotetext{
* Part of MVSc thesis submitted to Kerala Veterinary and Animal Sciences University, Pookode, Wayanad, Kerala

1. MVSc Scholar

2. Assistant Professor

3. Assistant Professor and Head (i/c)

4. Assistant Professor, CPPR, Mannuthy

5. Professor and Head, University Veterinary Hospital, Kokkalai,

${ }^{*}$ Corresponding author: nayanadevarajan93@gmail.com, Ph:9645797337
}

Copyright: (C) 2021 Nayana et al. This is an open access article distributed under the terms of the Creative Commons Attribution 4.0 International License (http://creativecommons.org/licenses/by/4.0/), which permits unrestricted use, distribution, and reproduction in any medium, provided the original author and source are credited. 
cervical patency pyometra can be either opencervix pyometra or closed-cervix pyometra. A stable pyometra at any time can be changed to an unstable one, hence the development of better prognostic markers are necessary. The markers which are considered regularly include clinical and haemato-biochemical parameters like anaemia, leucocyte count, blood urea nitrogen, serum creatinine, C-reactive protein (CRP), serum lactate, serum amyloid-A, serum endotoxin levels and prostaglandin $F_{2^{a}}$ metabolite (PGFM). Thus the laboratorial characterisation of haemato-biochemical parameters are of utmost importance in canine pyometra, as it provides valuable information regarding the clinical status of the animal during the day of presentation and after the initiation of medical treatment. Regular haematobiochemical monitoring in medically treated pyometra affected dogs will result in much favourable outcome.

\section{Materials and methods}

Dogs suffering from pyometra, presented to University Veterinary Hospital, Mannuthy and Kokkalai during the period from February 2019 to January 2020 were utilised for the study. These dogs were subjected to detailed clinico-gynaecological, ultrasonographic and laboratory evaluations for confirmation of the condition. Six dogs exhibiting sanguineous to mucopurulent vaginal discharge of varying consistency, colour, odour and with evidence of definite uterine sacculations on ultrasonography, were selected as animals with open-cervix pyometra (Group I) whereas six dogs which were not exhibiting any vaginal discharge, presented with other symptoms suggestive of pyometra and later confirmed with evidence of definite uterine sacculations on ultrasonography, were selected as animals with closed-cervix pyometra (Group II).

All the animals were administered with mifepristone @ 2.5mg/kg body weight orally twice daily for five days, followed by cloprostenol sodium @ $5 \mu \mathrm{g} / \mathrm{kg}$ body weight subcutaneously on every alternate day after ensuring cervical patency, till complete evacuation of uterus was assessed by ultrasonography. Adjunct antibiotics and fluid therapy were also given according to the condition of the animals.

A volume of $2 \mathrm{~mL}$ of peripheral blood sample was collected from all the dogs on the day of presentation (day 0) followed by days $3,7,14$ and 21 of treatment. Blood samples were processed within 3-4 hours of collection and haematological parameters like total erythrocyte count (TEC), total leucocyte count (TLC), thrombocyte count (TC), haemoglobin concentration $(\mathrm{Hb})$ and volume of packed red cells (VPRC) were assessed using automatic analyser (Mythic 18 Vet, Woodley, Switzerland). A volume of $5 \mathrm{~mL}$ of peripheral blood samples was collected from all the animals on days 0,3 , 7,14 and 21 into vacutainers with clot activator. Sera samples were separated, centrifuged, aliquotted and was immediately used for analysis of serum total protein (TP), albumin, blood urea nitrogen (BUN) and creatinine in a semiautomatic analyser (Erba Manheim, Chem-5 Plus V2, USA).

The data obtained were tabulated and analysed statistically (Snedecor and Cochran, 1994) using repeated measures ANOVA and SPSS version 21.

\section{Results and discussion}

Haematological parameters in Group I and II dogs are depicted in Table 1.

Mean total erythrocyte count in both the groups up to day 14 was less than the normal physiological value. There was a significant difference $(p<0.05)$ in mean erythrocyte count on day 21 in both the groups. The erythrocyte count came to normalcy by day 21 in both the groups. There was no significant difference ( $p>0.05)$ in mean erythrocyte count between the groups till day 14, but Group II exhibited an increase in the mean erythrocyte count on day 21 . Similarly lower values of TEC $(4.58 \pm 0.04$ to $4.99 \pm 0.01 \times 10^{6} / \mathrm{mm}^{3}$ ) were reported by Singh et al. (2006) among pyometra cases with acute inflammatory changes. Samantha et al. (2018) and Nath et al. (2009) suggested that in canine pyometra, the reason behind reduced TEC as reduced erythropoiesis due to the toxic suppression of bone marrow and loss of RBCs into the uterine lumen. 
Table 1. Haematological parameters on different days of observation in dogs affected with open and closed-cervix pyometra

\begin{tabular}{|c|c|c|c|c|c|c|}
\hline \multirow{2}{*}{ Parameter } & \multirow{2}{*}{ Gp } & \multicolumn{5}{|c|}{ Days of observation } \\
\hline & & Day 0 & Day 3 & Day 7 & Day 14 & Day 21 \\
\hline \multirow{2}{*}{$\begin{array}{c}\text { TEC } \\
\left(\times 10^{6} / \mathrm{mm}^{3}\right)\end{array}$} & 1 & $3.97^{a, x} \pm 0.46$ & $4.05^{\mathrm{a}, \mathrm{x}} \pm 0.42$ & $4.33^{a, x} \pm 0.42$ & $5.22^{a, x} \pm 0.40$ & $6.30^{\mathrm{b}, \mathrm{x}} \pm 0.27$ \\
\hline & II & $4.80^{a, x} \pm 0.23$ & $4.56^{a, x} \pm 0.32$ & $4.38^{a, x} \pm 0.40$ & $5.24^{\mathrm{a}, \mathrm{x}} \pm 0.43$ & $7.49^{b, y} \pm 0.40$ \\
\hline \multirow{2}{*}{$\begin{array}{c}\text { TLC } \\
\left(\times 10^{3} / \mathrm{mm}^{3}\right)\end{array}$} & $\mathrm{I}$ & $30.20^{a} \pm 4.71$ & $25.49^{\mathrm{ac}} \pm 3.42$ & $17.03^{\mathrm{bc}} \pm 2.46$ & $14.10^{b} \pm 2.46$ & $10.60^{b} \pm 1.74$ \\
\hline & II & $40.75^{a} \pm 5.43$ & $32.90^{\mathrm{a}} \pm 3.24$ & $22.53^{\mathrm{bc}} \pm 3.16$ & $17.76^{\mathrm{bc}} \pm 2.05$ & $9.15^{\text {bd }} \pm 0.90$ \\
\hline \multirow{2}{*}{$\begin{array}{l}\mathrm{Hb} \\
(\mathrm{g} / \mathrm{dL})\end{array}$} & $\mathrm{I}$ & $9.07^{a} \pm 1.40$ & $9.00^{a} \pm 1.34$ & $10.05^{a} \pm 1.15$ & $11.39^{b} \pm 1.10$ & $13.51^{b} \pm 0.61$ \\
\hline & II & $10.35^{a} \pm 0.71$ & $9.48^{a} \pm 0.72$ & $9.75^{a} \pm 0.76$ & $11.45^{\mathrm{ac}} \pm 0.51$ & $12.83^{\mathrm{bc}} \pm 0.54$ \\
\hline \multirow{2}{*}{$\begin{array}{c}\text { VPRC } \\
(\%)\end{array}$} & $\mathrm{I}$ & $24.60^{a} \pm 3.50$ & $26.04^{\mathrm{a}} \pm 2.68$ & $32.31^{\mathrm{ac}} \pm 3.77$ & $34.25^{\mathrm{ac}} \pm 3.23$ & $40.30^{\mathrm{bc}} \pm 1.57$ \\
\hline & II & $25.75^{a} \pm 3.31$ & $26.90^{\mathrm{a}} \pm 2.30$ & $28.22^{a} \pm 2.09$ & $33.92^{\mathrm{bc}} \pm 0.75$ & $40.22^{\mathrm{bd}} \pm 0.87$ \\
\hline \multirow{2}{*}{$\begin{array}{c}\text { TC } \\
\left(\times 10^{3} / \mathrm{mm}^{3}\right)\end{array}$} & 1 & $162.17^{a} \pm 26.00$ & $194.17^{\mathrm{ac}} \pm 54.97$ & $255.52^{\mathrm{ad}} \pm 48.43$ & $335.19^{\mathrm{bcd}} \pm 49.82$ & $396.36^{\mathrm{b}} \pm 31.60$ \\
\hline & II & $169.50^{\mathrm{a}} \pm 31.70$ & $201.17^{a} \pm 26.06$ & $249.33^{\mathrm{ac}} \pm 27.66$ & $339.17^{\mathrm{bc}} \pm 41.08$ & $364.50^{\mathrm{b}} \pm 37.43$ \\
\hline
\end{tabular}

abcd Different superscripts in a row differ significantly $(p<0.05)$

xy Different superscripts in a column between groups differ significantly $(p<0.05)$

Mean total leucocyte count on the day of presentation was higher than the normal range in both the groups. There was a significant reduction $(p<0.05)$ in total leucocyte count from day 7 of observation in both the groups. A highly significant difference $(p<0.01)$ in mean total leucocyte count could be observed on day 0 and day 21 in both the groups. The results were in accordance with Vidya et al. (2020) where the mean TLC $\left(\times 10^{3} / \mathrm{mm}^{3}\right)$ of pyometra affected dogs were $36.46 \pm 4.51,32.06 \pm 4.66,20.93 \pm 2.27$ and $17.33 \pm 1.45$, respectively on days $0,3,7$ and 14. Fransson et al. (1997) and Verstegen et al. (2008) reported leucocytosis in pyometra with neutrophilic leucocytosis and shift to left due to severe bacterial infection with resultant release of immature neutrophils from bone marrow to the circulation.

Mean haemoglobin concentration was less than the normal physiological range on all the days except day 21 in both the groups. There was a significant increase $(p<0.05)$ in haemoglobin concentration from day 14 in Group I as well as Group II. There was a significant increase $(p<0.05)$ in the haemoglobin level from day of presentation and day 21 in both the groups. There was no significant $(p>0.05)$ difference in haemoglobin concentration between the treatment groups.
Almost similar results were obtained for $\mathrm{Yu}$ (2012), in a study conducted in open-cervix and closed-cervix pyometra groups and recorded as $11.73 \pm 0.70$ and $11.80 \pm 0.68 \mathrm{~g} / \mathrm{dL}$, respectively. The reason behind the reduced haemoglobin concentration in pyometra affected animals was the iron sequestration inside the myeloid cells in bone marrow which was mediated by lactoferrin and other acute phase proteins (Nelson and Couto, 1992).

The VPRC was subnormal in both the groups except for the last day of observation. In Group I there was no significant difference ( $p>0.05)$ in mean VPRC between days $0,3,7$ and 14 , but a significant difference $(p<0.05)$ existed between day 21 and other days of observation. In Group II there was no significant ( $p>0.05$ ) difference in mean VPRC between days 0,3 and 7 but a significant difference occurred from day 14 of observation. A highly significant increase $(p<0.01)$ in mean VPRC existed in day 21 in Group II. There was no significant difference $(p>0.05)$ in mean VPRC between days of observation between groups. Similar values were obtained for Vidya (2019), in which the mean per cent of VPRC of pyometra affected dogs were $25.43 \pm 1.66,23.96 \pm 1.86$, $23.90 \pm 1.73$ and $25.54 \pm 1.64$, respectively on days $0,3,7$ and 14. According to Unnikrishnan et al. (2020) low VPRC in the study of pyometra 
affected animals was explained as a reflection of reduced TEC, caused by bone marrow suppression by toxins and resultant reduction in erythropoiesis.

Mean thrombocyte count on all the days of observation in both Group I and Group II were within the normal range. A gradual increase in the mean thrombocyte count could be observed in both the groups from the initiation of treatment. A significant increase $(p<0.05)$ in mean thrombocyte count could be observed from day 14 in both the groups. There was no significant difference ( $p>0.05$ ) between days of observation between groups could be observed. Similar observations were recorded in the literature by various researchers including Shah et al. (2017). According to the author, improvement in thrombocyte count could be considered as a better prognostic factor.

Serum biochemical parameters in Group I and II dogs are depicted in Table 2.

Mean serum total protein levels were observed to be within the normal physiological limit in all the days of observation in both the groups. There was no significant difference $(p>0.05)$ in total serum protein concentration in any of the days of observation in Group I. Even though within the normal range, a significant reduction $(p<0.05)$ in protein level existed in day 21 in Group I and Group II. There was no significant difference $(p>0.05)$ in mean serum protein level between the days of observation between the groups, but the total protein concentration was higher in Group II than in Group I in all the days of observation. In a similar study conducted by Hardy and Osborn (1974) 82.30 per cent of pyometra affected animals showed normal serum protein levels on all the days of observation.

Mean serum albumin concentration in all the days of observation in both the groups were within the normal range. There was no significant difference $(p>0.05)$ in mean serum concentration existed in both the groups and between the groups in any day of observation. This finding was in accordance with Lakshmikanth (2016).

Mean serum BUN concentration was within the normal range in both the groups in all the days of observation. There was no significant difference $(p>0.05)$ in mean BUN concentration in any of the days of observation in Group I. In Group II there was a significant reduction $(p<0.05)$ in mean serum BUN concentration in day 14. There was no significant difference ( $p>0.05)$ between the groups in the level of mean serum BUN concentration on various days of observation. The results were in accordance with Lakshmikanth (2016). Mean serum creatinine levels in both the groups were within the normal range in all the days of observation. There was no significant ( $p>0.05)$ difference in levels of serum creatinine in any day of observation within the groups and between the groups. The result was in accordance with Vidya et al. (2020) and Unnikrishnan et al. (2020).

Table 2. Serum biochemical parameters on different days of observation in dogs affected with open and closed-cervix pyometra

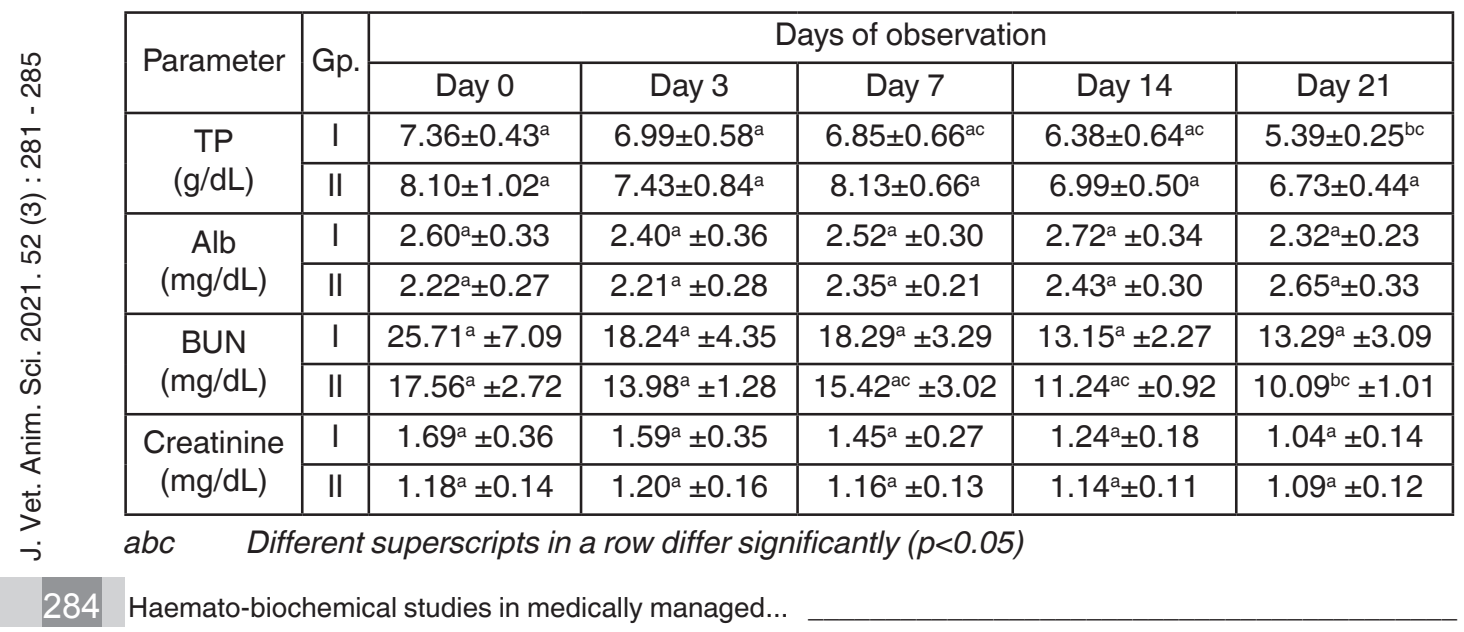


Results of normal serum biochemical values indicate unaffected or mildly affected hepatic and renal functions Vidya et al. (2020).

\section{Conclusion}

The study showed that TEC, TLC, $\mathrm{Hb}$ concentration, VPRC and thrombocyte count could be used as a prognostic tool for evaluating the response to medical management of pyometra in dogs affected with open and closed cervix pyometra.

\section{Acknowledgement}

The authors are thankful to Kerala Veterinary and Animal Sciences University for providing all facilities for the completion of this work.

\section{Conflict of interest}

The authors declare that they have no conflict of interest.

\section{References}

Fransson, B., Lagerstedt, A.S., Hellmen, E. and Jonsson, P. 1997. Bacteriological findings, blood chemistry profile and plasma endotoxin levels in bitches with pyometra or other uterine diseases. J. Vet. Med. A. 44(7): 417-426.

Hardy, R.M. and Osborne, C.A. 1974. Canine pyometra: pathophysiology, diagnosis and treatment of uterine and extrauterine lesions. J. Am. Anim. Hosp. Ass.10: 245-267.

Lakshmikanth, T.R. 2016. Physiological and hematobiochemical changes in open and closed pyometra in female dogs. Ph.D thesis. Karnataka Veterinary, Animal and Fisheries Sciences University, Bidar, $133 p$.

Nath, K., Tiwari, S.K. and Kalim, O. 2009. Physiological and haematological changes in bitches with Pyometra. Indian. Vet. J. 86: 734-736.
Nelson, R. and Couto, G. 1992. Small Animal Internal Medicine. (2 ${ }^{\text {nd }}$ Ed.). St Louis, Mosby, 870p.

Samantha, G., Sarath, T., Monica, G., Arunmozhi, N., Sridevi, P and Joseph, C. 2018. Ultrasonographic and haemato-biochemical evaluation of bitches affected with cystic endometrial hyperplasia-pyometra complex. Int. J. Curr. Microbiol. App. Sci. 7: 2327-2338.

Shah, S.A., Sood, N.K., Wani, B.M., Rather, M.A., Beigh, A.B. and Amin, U. 2017. Haemato-biochemical studies in canine pyometra. J. Pharmacogn. Phytochem. 6(4): 14-17.

Singh, S., Dadhich, H. and Sharma, G.D. 2006. Haemato-biochemical studies in cystic endometrial hyperplasia pyometra complex in canine. Indian J. Vet. Pathol. 30: 46-48.

Unnikrishnan, M.P., Kurien, M.O., Jayakumar, C., Harshan, H. M, John Martin K.D. and Unny M. N. 2020. Haematological evaluation of medically treated cases of pyometra in dogs. J. Vet. Anim. Sci. 51(1): 1-7.

Verstegen, J., Dhaliwal, G. and VerstegenOnclin, K. 2008. Mucometra, cystic endometrial hyperplasia, and pyometra in the bitch: Advances in treatment and assessment of future reproductive success. Theriogenology. 70: 364-374.

Vidya, V.K., Unnikrishnan, M.P., Kurien, M.O., Jayakumar, C. and Surya, S. 2020. Comparative analysis of closed and open-cervix canine pyometra. J. Vet. Anim. Sci. 51(2): 153- 158.

Yu, I.L. 2012. Hematological and serum chemical characteristics of open cervix and closed cervix pyometra in bitches. J. Anim. Vet. Adv. 11(19): 3658-3661. 